\title{
Influenza surveillance $1972-75$
}

\author{
By the Public Health Laboratory Service Standing \\ Advisory CoMmittee on INFLUENZA*
}

(Received 10 August 1976)

\begin{abstract}
SUMMARY
The surveillance programme described in an earlier report was used to monitor outbreaks of influenza in three successive winters. Influenza virus A was active in all of them, but the only major outbreak of influenza $B$ was in 1973-4. The highest incidence of influenza $A$ was in the $0-4$ age group in all three winters, but schoolchildren bore the brunt of infections by influenza virus $B$.
\end{abstract}

\section{INTRODUCTION}

The influenza surveillance programme developed by the Public Health Laboratory Service (1975) in the winter of 1971-72 was used as the basis of a collaborative study over the three subsequent winters. The directors of 17 Public Health laboratories participated in 1972-3 and recruited general practitioners and Medical Officers of Health to collect specimens and information; one laboratory dropped out in each of the two following winters. The Epidemiological Research Laboratory was responsible for the collection and collation of information and for the analysis of the results.

\section{METHODS}

Information was collected from the beginning of November each year to the end of March in 1973 and to the end of April in 1974 and 1975.

\section{Local statistics}

Each participating laboratory collaborated with at least one general practice. The general practitioners kept registers of their patients by age and sex which were brought up to date at least once a year. The individuals so registered formed the surveillance population. The number under surveillance in each winter was:

$$
\begin{array}{ll}
1972-3 & 162746 \\
1973-4 & 140001 \\
1974-5 & 130884
\end{array}
$$

The general practitioners recorded first consultations for acute respiratory disease daily by age group. They took nose and throat swabs from an agreed

* The members of the Committee were: Dr P. G. Mann (Chairman), Dr J. W. G. Smith (Secretary), Dr R. J. C. Hart, Dr C. H. L. Howells, Dr Hélène J. Mair, Dr E. R. Mitchell, Dr M. T. Parker, Dr Marguerite S. Pereira, Dr W. N. Dunnet (Department of Health and Social Security), Professor D. L. Miller (Middlesex Hospital Medical School, London). 
minimum number of these patients each week. Swabs were taken as far as possible from randomly selected patients. There was no selection of patients diagnosed clinically as influenza. The swabs were sent to the laboratory in virus transport medium as quickly as possible.

The numbers of deaths from all causes by age groups were notified weekly by Medical Officers of Health and, after reorganization in 1974, by District Community Physicians (D.C.P.s). The population of each district recorded in the 1971 census was divided into the same age groups.

Numbers of new claims to sickness benefit were sent by the staff of local offices of the Department of Health and Social Security or by the Medical Officer of Health (D.C.P.).

Influenza virus isolations were made by inoculating the nose and throat swabs taken by the general practitioners into secondary rhesus monkey kidney cell cultures. Initial identification of viruses was carried out locally, but most strains were sent to the Virus Reference Laboratory so that their characteristics could be investigated more fully.

\section{National statistics}

The Royal College of General Practitioners (R.C.G.P.) kindly provided analyses of the consultation rates for 'epidemic influenza' collected by their research unit from over 60 practitioners throughout the country. The total deaths from all causes were obtained from the Registrar General's returns.

Weekly numbers of new claims for sickness benefit were given by the Department of Health and Social Security. Excess new sickness benefit claims were calculated by subtracting the number of new claims recorded in 1970-1, when there was little or no influenza in the country, from the number recorded for the same week in the year being studied.

The numbers of isolations of influenza viruses reported by Public Health and hospital laboratories to the P.H.L.S. Communicable Disease Report (C.D.R.) were supplied by the Epidemiological Research Laboratory.

\section{The virologically estimated influenza rate}

This new statistic, expressed as the rate per 100000 at risk, was obtained by multiplying together the general practice consultation rate for acute respiratory infections and the percentage of swabs collected by general practitioners that yielded influenza virus. It was used to indicate differences in the incidence of influenza in different localities and between age groups as well as for the whole population included in the scheme.

\section{RESULTS}

The effects of influenza nationally winter by winter are shown in Fig. 1. The three winters in the present study can be compared with 1970-1 when there was virtually no influenza and 1969-70 when the A/Hong Kong virus caused a large outbreak. Influenza was not particularly troublesome in any of the three winters, 

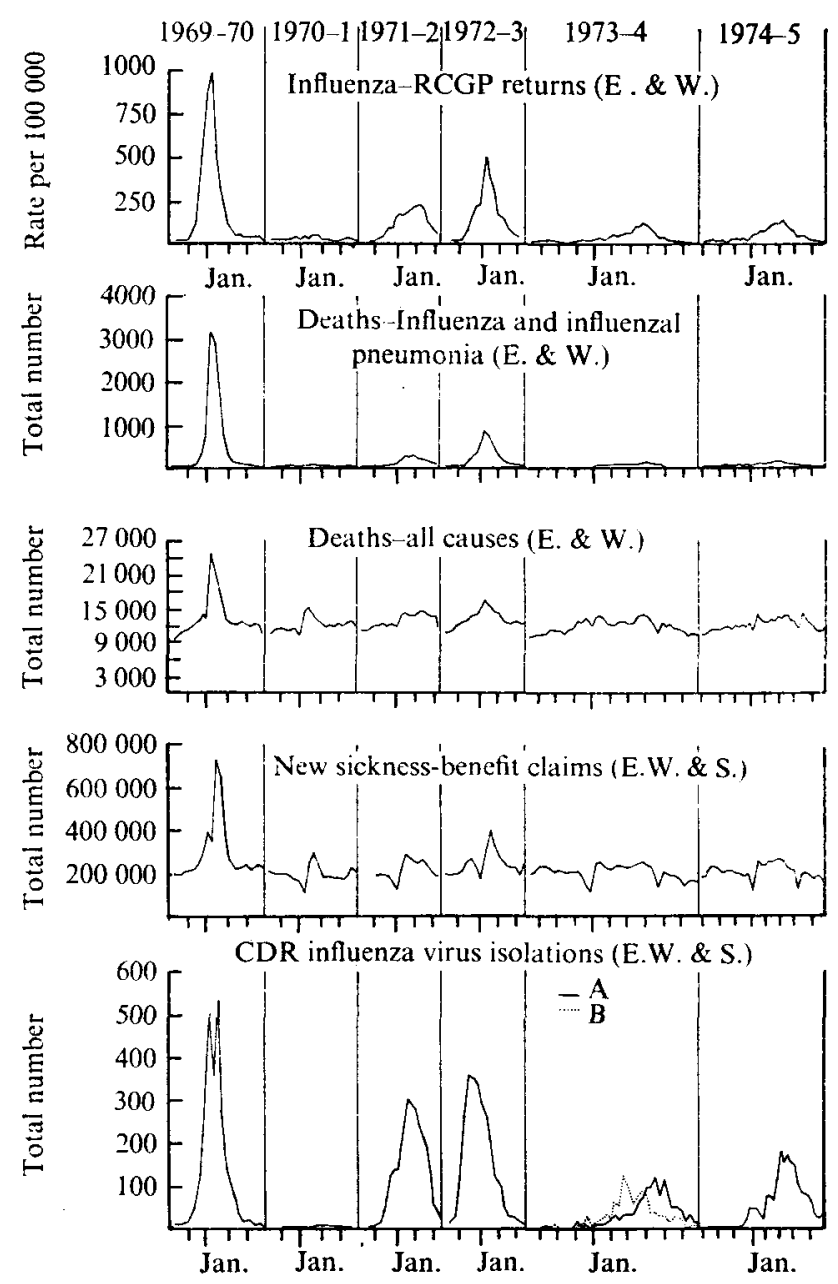

Fig. 1. National statistics.

although in 1972-3 there were many cases reported by general practitioners and there was an associated increase in mortality and in the number of new claims to sickness benefit (Fig. 1). More detailed information from the present study (Fig. 2) shows the information obtained from general practices and the virologically estimated influenza rate during the three winters.

\section{Influenza in 1972-3}

The A/England/42/72 strain, which was isolated from early November to the end of February in participating laboratories, gave rise to a moderate epidemic. Total deaths and consultation rates rose sharply in late November and early December to a peak in week 50 ending on 16 December, after which they fell gradually until the end of February.

The numbers of consultations for acute respiratory illness by age group are shown in Table 1, which also gives the virologically estimated influenza rate. 

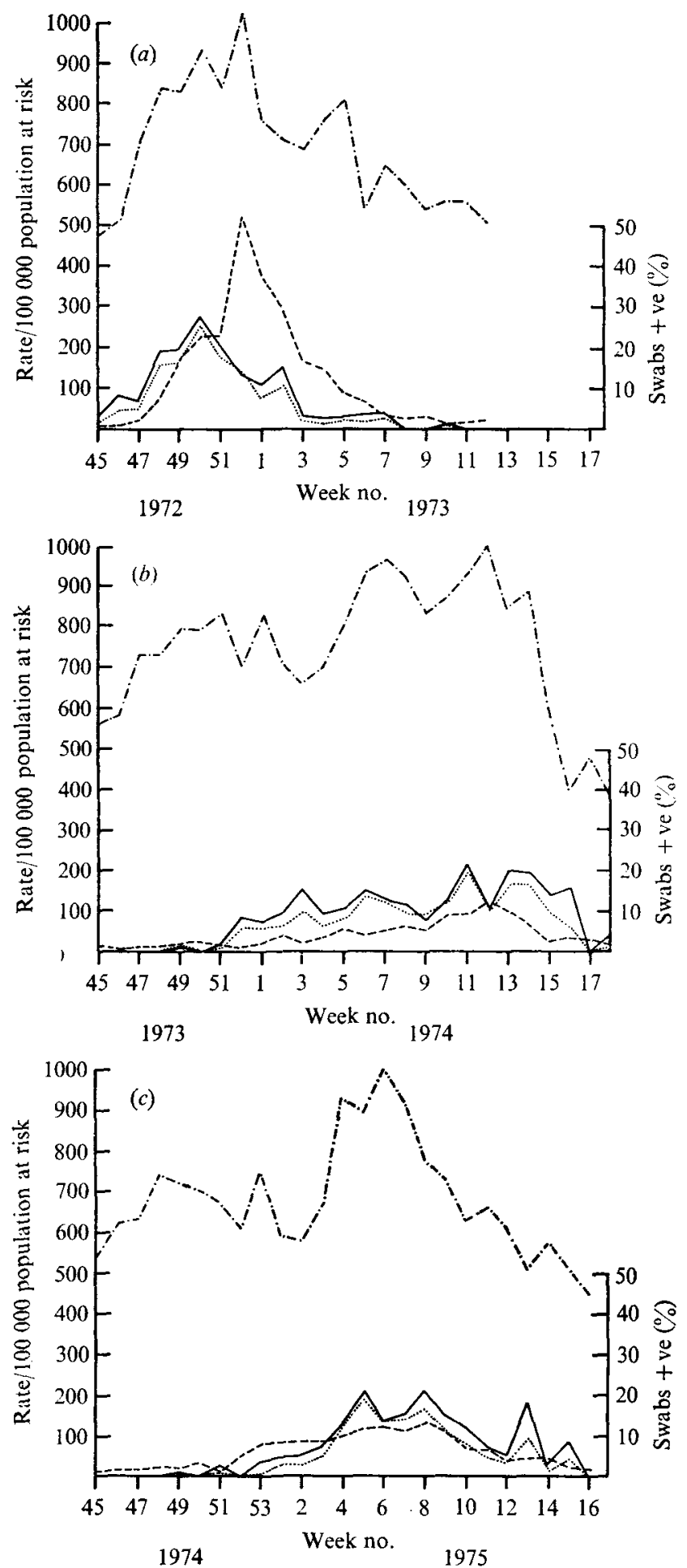

Fig. 2. Observations from general practices. ---, Acute respiratory illness surveillance practices. - - , Influenza incidence recorded by R.C.G.P. ——, Percentage of swabs positive for influenza virus......., Virologically estimated influenza rate. 
Table 1. Age distribution of first consultations for acute respiratory illness from week 44 (1972) to 13 (1973) and virus culture results

\begin{tabular}{|c|c|c|c|c|c|c|}
\hline & \multicolumn{6}{|c|}{ Age group (years) } \\
\hline & $0-4$ & $5-14$ & $15-24$ & $25-44$ & $45-64$ & $\begin{array}{l}65 \text { and } \\
\text { over }\end{array}$ \\
\hline Number of persons $\ldots$ & 14476 & 28038 & 23007 & 45539 & 32636 & 18621 \\
\hline $\begin{array}{l}\text { Acute respiratory illness: } \\
\text { Rate per } 100000 \text { in } \\
\text { surveillance practices }\end{array}$ & 46530 & 17780 & 12530 & 10560 & 9420 & 9610 \\
\hline No. of swabs examined & 334 & 602 & 561 & 696 & 417 & 128 \\
\hline$\%$ swabs + ve for influenza $\mathrm{A}$ & $6 \cdot 6$ & $7 \cdot 5$ & $12 \cdot 1$ & $10 \cdot 3$ & $10 \cdot 8$ & $13 \cdot 2$ \\
\hline $\begin{array}{l}\text { Virologically estimated } \\
\text { influenza rate per } 1000\end{array}$ & 3070 & 1330 & 1520 & 1090 & 1020 & 1280 \\
\hline
\end{tabular}

Influenza appears to have attacked the 0- to 4-year groups most severely and the 25- to 64-year groups least. Geographically, the virus appeared first in Bath in late September. A few isolations were reported from various laboratories in October-including a school outbreak in Dorchester - but isolations were first reported in appreciable numbers in the London area in early November, reaching a peak in week 48. Isolations were reported from other parts of the country, especially the Midlands, in increasing numbers, and the virus was reported from most of England and Wales by week 50.

The observations made from the areas collaborating in the surveillance tended to confirm this pattern with one or two exceptions. In Liverpool, for example, influenza virus was first recovered from the collaborating practice in week 50, later than in other Midland areas. The effect on sickness benefit claims and consultations for acute respiratory disease confirmed that Liverpool experienced influenza later than most other centres.

The spread of influenza may also be inferred from the returns to the Registrar General of deaths attributed to influenza and influenzal pneumonia. These are classified by counties for England and Wales, and the weekly death rates may be standardized by age for each county. Noticeably increased death rates from influenza were first reported from London in week 48 of 1972 with a peak in week 50. By this time the home counties also were reporting influenza deaths, together with some of the Midland counties - Leicestershire, Warwickshire and Staffordshire. By week 52, 1972, the returns indicated that influenza was affecting all counties. Outside London and the home counties the highest influenza death rates were reported in either week 1 or 2 of 1973, and in Hereford, Shropshire and parts of North Wales the peak was in week 3.

The pattern of spread indicated from the mortality returns resembles that shown by virus isolations with the exception that the fairly early involvement of the South coast was not apparently reflected in mortality. The peaks of deaths were recorded about 2 weeks later than the peaks in virus isolation.

As the influenza A outbreak died down in January 1973, influenza B infections 


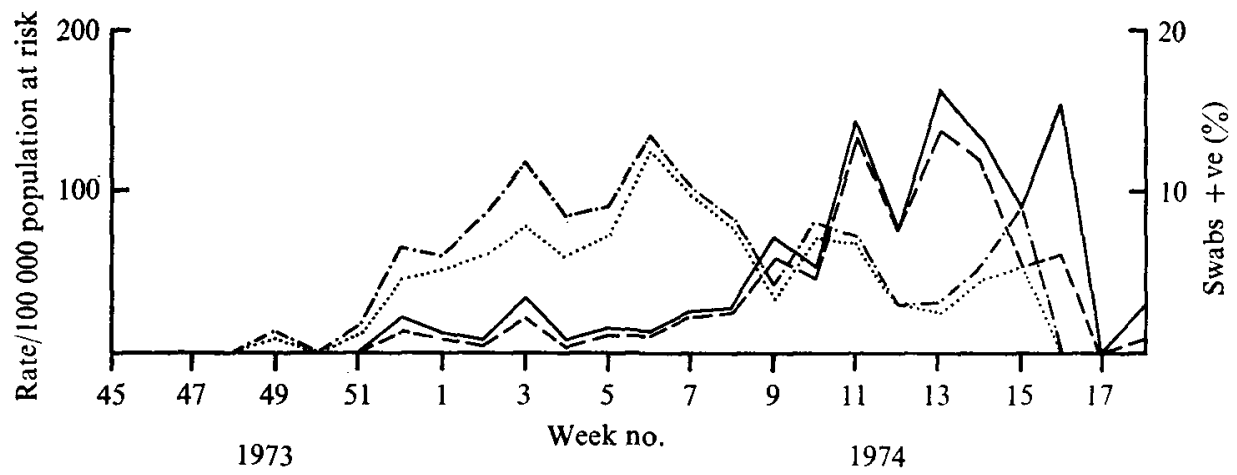

Fig. 3. Incidence of influenza viruses $A$ and $B$ in general practices. _- , Percentage of swabs + ve to influenza $A$ virus. - - -, Virologically estimated influenza $A$ rate. -.-, Percentage swabs + ve to influenza $B$ virus. ......, Virologically estimated influenza $B$ rate.

Table 2. Age distribution of first consultations for acute respiratory illness from week 45 (1973) to 18 (1974) and virus culture results

\begin{tabular}{|c|c|c|c|c|c|c|}
\hline & & & Age grou & (years) & & \\
\hline & $0-4$ & $5-14$ & $15-24$ & $25-44$ & $45-64$ & $\begin{array}{l}65 \text { and } \\
\text { over }\end{array}$ \\
\hline Number of persons $\ldots$ & 12117 & 25524 & 19742 & 39586 & 27514 & 14969 \\
\hline $\begin{array}{l}\text { Acute respiratory illness: } \\
\text { Rate per } 100,000 \text { in } \\
\text { surveillance practices }\end{array}$ & 62400 & 27100 & 16200 & 12600 & 11100 & 11100 \\
\hline No. of swabs examined & 360 & 698 & 461 & 812 & 367 & 89 \\
\hline$\%$ swabs + ve for influenza $A$ & $2 \cdot 2$ & $2 \cdot 2$ & $3 \cdot 0$ & $4 \cdot 6$ & $4 \cdot 4$ & $3 \cdot 4$ \\
\hline $\begin{array}{l}\text { Virologically estimated } \\
\text { influenza A rate per } 100,000\end{array}$ & 1370 & 600 & 490 & 580 & 490 & 380 \\
\hline$\%$ swabs + ve for influenza $B$ & $\mathbf{2 \cdot 8}$ & $8 \cdot 6$ & $3 \cdot 5$ & $3 \cdot 3$ & $3 \cdot 8$ & $4 \cdot 5$ \\
\hline $\begin{array}{l}\text { Virologically estimated } \\
\text { influenza B rate per } 100,000\end{array}$ & 1750 & 2330 & 570 & 420 & 420 & 500 \\
\hline $\begin{array}{l}\text { Virologically estimated } \\
\text { influenza A \& B rate per } \\
100,000\end{array}$ & 3120 & 2930 & 1060 & 1000 & 910 & 880 \\
\hline
\end{tabular}

began to appear. Although the virus was widespread and there were outbreaks in schools, the number of infections reported was not large. Only in the Exeter area were the surveillance practices affected. At the height of the outbreak their respiratory consultation rate in the 5-14 age group was about three times the winter's average, but the consultation rates in the other age groups were not increased.

\section{Influenza in 1973-4}

There was relatively little clinical evidence of influenza during this winter (see Fig. $2 b$ ) although the A/Port Chalmers/1/73 strain of influenza $A$, the B/Hong Kong/5/72 and intermediate influenza $B$ strains were circulating in the population. 
Table 3. Age distribution of first consultations for acute respiratory illness from week 45 (1974) to 16 (1975) and virus culture results

\begin{tabular}{|c|c|c|c|c|c|c|}
\hline & \multicolumn{6}{|c|}{ Age group (years) } \\
\hline & $0-4$ & $5-14$ & $15-24$ & $25-44$ & $45-64$ & $\begin{array}{c}65 \text { and } \\
\text { over }\end{array}$ \\
\hline Number of persons $\ldots$ & 10731 & 22904 & 18952 & 36710 & 25946 & 14947 \\
\hline $\begin{array}{l}\text { Acute respiratory illness: } \\
\text { Rate per } 100000 \text { in } \\
\text { surveillance practices }\end{array}$ & 64800 & 22900 & 15900 & 12900 & 9800 & 8900 \\
\hline No. of swabs examined & 315 & 506 & 400 & 632 & 291 & 80 \\
\hline$\%$ swabs + ve for influenza $\mathrm{A}$ & $7 \cdot 6$ & $7 \cdot 7$ & $6 \cdot 3$ & $8 \cdot 4$ & $9 \cdot 6$ & $8 \cdot 8$ \\
\hline Virologically estimated & 4930 & 1760 & 1000 & 1080 & 940 & 780 \\
\hline
\end{tabular}

Fig. 1 shows these viruses had little effect on numbers of deaths or new claims to sickness benefit.

The outbreak of influenza $B$ began at the end of November and reached its peak in mid-February. Influenza $A$ began in December, stayed at a very low level while influenza B was increasing, and reached maximum incidence in March and April (Fig. 3).

The incidence of illness caused by influenza $A$ was highest in the 0-4 age group, and by influenza $B$ in the 5-14 age group (Table 2).

Geographically the outbreak was patchy in its distribution. There appears to have been little influenza A in Cardiff, Carlisle, Liverpool, Nottingham or Salisbury but it was prevalent in other areas such as Bath, Derby, Epsom and Shrewsbury. In Bristol and Manchester, influenza virus $A$ was isolated only from sources outside the surveillance practices. Most isolations of influenza virus $B$ came from the western part of England - Bath, Gloucester and Shrewsbury in December and Bristol and Manchester in late January. Very few isolations were reported from other laboratories such as Carlisle, Chester, Derby, Epsom, Nottingham and Salisbury. No isolations of influenza virus B were recorded from the surveillance practices in Exeter, in which the same strain of virus was isolated the previous winter, though the virus was isolated from other patients in the area.

\section{Influenza in 1974-5}

The incidence of influenza $A$ this winter was more than twice that in the previous winter, judging by the virologically estimated influenza rates shown in Tables 2 and 3. The viruses responsible were $A /$ Port Chalmers/1/73 and $A / S c o t l a n d / 840 / 74$ with some strains intermediate in antigenic structure between them. The relative incidence of infection caused by these viruses did not change during the winter. There were no isolations of influenza virus $B$ from patients in the surveillance practices, but 8 were reported to the C.D.R. from all sources.

As in the previous winter, influenza $A$ occurred late in the season. There were few isolations before January, the highest incidence was in February and March, and there were appreciable numbers of cases in April. 


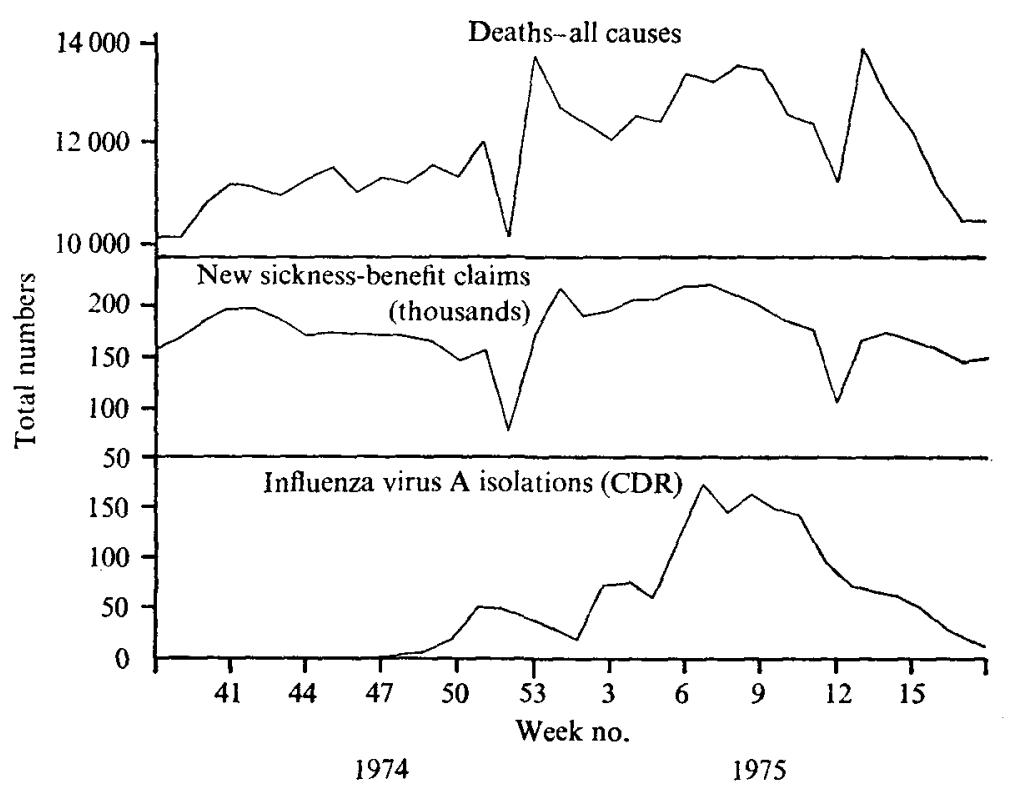

Fig. 4. Relationships between isolations of influenza $A$ and some national statistics for England and Wales, 1974-5.

Table 3 shows that the highest incidence of illness leading to consultation with the general practitioners was again in the $0-4$ age group. The excess number ( 0.8 million) of new claims to sickness benefit was slightly higher than in the previous winter, and there was a clear increase in the number of deaths from all causes during the weeks 4-12 when the prevalence of influenza virus was greatest (Fig. 4).

The virus was first isolated from a surveillance practice in Gloucestershire in week 49 (1974), but isolations from all surveillance practices did not rise above 5 per week until week $4(1975)$. The incidence of influenza indicated by the virologically estimated influenza rate suggests that the outbreak may have been more severe in Bath, Gloucester, Leicester and Manchester than in Cardiff, Carlisle and Liverpool.

\section{DISCUSSION}

The pilot study in the first quarter of 1972 (Public Health Laboratory Service, 1975) enabled us to suggest a plan for surveillance which it was hoped would provide useful information on differences between communities in the timing and impact of influenza, on differences between outbreaks and on the relative vulnerability of different age groups. The plan was put into action during the three winters and the information was collected and analysed locally in each participating laboratory as well as being sent to the Epidemiological Research Laboratory. Participating laboratories kept up-to-date graphs or histograms which were circulated weekly to those who contributed information and specimens.

In each winter, most of England and Wales was affected; there was some local 
variation in the behaviour of influenza but there was no evidence of appreciable differences between regions. A single isolation of the A/England/42/72 strain was identified in England in January 1972. It caused outbreaks in the Southern Hemisphere in the succeeding months, and was responsible for the winter influenza in Britain in 1972 3, which finished at the end of January. The outbreaks of influenza $\mathrm{A}$ in the following two winters continued into April, and it is not clear why the A/England/42/72 strain failed to cause an outbreak in the spring of 1972 . The strain causing the outbreak in each winter had been first isolated in England some months previously. It is possible that influenza viruses, like enteroviruses (Hart \& Miller, 1973), are seeded in the population some time before they cause outbreaks.

The virologically estimated influenza rate is derived from information obtained in a uniform manner from general practices and should be a sensitive indicator of the incidence of influenza in the community. There is a possibility of bias because patients, only a proportion of whom were swabbed, selected themselves by consulting their general practitioners. All swabs were taken within 5 days of onset of the illness. During this time it has been shown (Higgins, Ellis \& Boston, 1966; Poole \& Tobin, 1973) that there is no appreciable fall in isolation rates. Although there were minor differences in techniques between laboratories, rhesus monkey kidney cells from a single source were used for virus isolation. Comparisons of the incidence of influenza can therefore be made from year to year and between different localities and age groups. Because the rate is based on the isolation of virus from nose and throat swabs, the figure must be an underestimate of the true incidence of infection, since failures to isolate virus result from imperfections in swab-taking, transport or in laboratory procedures. The extent by which the incidence of influenza exceeds the virologically estimated rate is not known, but in week 50 of 1972, influenza virus was isolated from almost a third of all swabs taken, so the true incidence could not be more than three times the virologically estimated rate. If it is accepted that the true incidence of clinical influenza, sufficiently severe to cause consultation with the family doctor, is about twice that indicated by the virologically estimated influenza rate, it may be estimated that $3.0 \%$ of the population of England and Wales was affected by the disease in $1972-3,3.2 \%$ in $1973-4(1.4 \%$ influenza $A, 1.8 \%$ influenza $B)$ and $2.8 \%$ in 1974-5. The virologically estimated influenza rates for the different age groups are shown in the tables. The total incidence of infection by influenza viruses must have been considerably higher because these figures do not take subclinical infections into account. Miller et al. (1973) reported that about half the subjects in their prospective study who showed serological evidence of infection had no recorded illness.

Influenza was not particularly troublesome in any of the three winters but the outbreak of 1972-3 was by no means small; inspection of Fig. 1 suggests that the peak was about half the size of that in the major 1969-70 outbreak. Strains of influenza virus $A$ were active in each winter, but the weekly virologically estimated influenza rate exceeded 200 per 100000 only once - in week 50 of 1972. The outbreaks lasted about 10-12 weeks, but virus was isolated from a few 
patients before and after the main outbreak. In 1972-3 there was a sharp increase in deaths and new claims to sickness benefit at the time when influenza virus $A$ was active (Fig. 1) and there were smaller increases during the two succeeding winters. The peaks of deaths were recorded about 2 weeks later than the peaks in virus isolation, a pattern observed in the United States (Report, 1971). The more detailed information collected from general practitioners suggests that in each winter about $2 \%$ of the working-age population had an attack of clinical influenza, but this was less obvious in 1973-4 and 1974-5 because the peaks were lower and the duration of the outbreaks longer. The number of swabs taken by general practitioners from patients in the over 65 group was smaller than in the other groups. It may be that some elderly patients did not consult their doctors during the first 5 days of illness, and so were not swabbed.

The records of first consultations for acute respiratory disease by the general practitioners taking part in this scheme, and the incidence of influenza recorded by the R.C.G.P., shown in Fig. 2, were comparable during the early part of the outbreaks but there appeared to be a tendency for over-reporting of influenza in the R.C.G.P. scheme after the outbreak had passed its peak.

The highest incidence of clinical influenza $A$ in each winter was in the 0-4 age group; there was no pronounced difference in incidence among the other age groups. The figures depended on consultations with general practitioners and it could be suggested that they would be biased because infants and young children would be brought to see their doctors more often than older children and adults. However, the more intensive observation of a smaller population in the Tecumseh study in 1966-71 (Monto \& Kioumehr, 1975) also showed that the highest incidence of influenza $A$ was in the youngest children. They found that the highest incidence of influenza $B$ was in the 5-14 year olds, and we estimated the influenza $B$ rate in this age group in 1973-4 as 2330 , considerably higher than in any other age group (see table 2) and in sharp contrast with the comparatively low rates for influenza $A$ in this group during the three winters. The high incidence of influenza $B$ in this age group is consistent with the fact that the virus causes serious outbreaks in schools.

The difference in age groups attacked by the two viruses is interesting. The selective attack by influenza virus $B$ on children of school age has not yet been explained satisfactorily. Miller \& Lee (1969) suggested that influenza virus B was found most often in schoolchildren in 1967-8 because the last major epidemic of influenza B had been in 1962. Hall, Cooney \& Fox (1973), on the other hand, found many reinfections and considered that infections with influenza virus $B$ conferred little, if any, lasting immunity. It is noteworthy that the latter found a slightly higher incidence of infections with both $A$ and $B$ viruses in the 2-5 age group than in the $0-1$ year olds, and it would probably be useful to divide the under 5 year olds into two groups in future studies. Miller, Pereira \& Clarke (1971) found the incidence of influenza $A$ in 1968-9 highest in children under 5 and low in the 5-14 age group; they drew attention to the high attack rate in adults. It is possible that young children are important disseminators of this virus, and their role requires further investigation. 
The directors and staffs of the public health laboratories at Bath, Bristol, Cardiff, Carlisle, Chester, Derby, Epsom, Exeter, Gloucester, Leicester, Liverpool, London (Central Middlesex Hospital), Manchester, Nottingham, Portsmouth, Salisbury and Shrewsbury took part in the study. We are extremely grateful to the 76 general practitioners who participated, and to the district community physicians and their staffs who supplied information.

\section{REFERENCES}

HaIL, C. E., Cooney, M. K. \& Fox, J. P. (1973). The Seattle virus watch. IV. Comparative epidemiologic observations of infections with influenza $A$ and $B$ viruses, 1965-1969 in families with young children. American Journal of Epidemiology 98, 365.

HaRT, R. J. C. \& MrrLeR, D. L. (1973). Echovirus 17 infections in Britain 1969-71. Lancet ii, 661 .

Higans, P. G., Eutis, E. M. \& Boston, D. G. (1966). The isolation of viruses from acute respiratory infections. III. Some factors influencing the isolation of viruses from cases studied during 1962-1964. Monthly Bulletin of the Ministry of Health and the Public Health Laboratory Service 25, 5.

Muler, D. L. \& LEE, J. A. (1969). Influenza in Britain 1967-68. Journal of Hygiene 67, 559.

Milleer, D. L., Pereira, M. S. \& Clarke, M. (1971). Epidemiology of the Hong Kong/68 variant of influenza A2 in Britain. British Medical Journal i, 475.

Milleg, D. L., Reid, D., Diamond, J. R., Permira, M. S. \& Chakraverty, P. (1973). Influenza in the Royal Air Force 1968-70. Journal of Hygiene 71, 535.

Monto, A. S. \& Krodmerr, F. (1975). The Tecumseh study of respiratory illness. IX. Occurrence of influenza in the community. American Journal of Epidemiology 102, 553.

Poowe, P. M. \& ToBIs, J. H. (1973). Viral and epidemiological findings in MRC/PHLS surveys of respiratory disease in hospital and general practice. Postgraduate Medical Journal 49, 778.

Publio Healith Laboratory Skrvice (1975). A programme for collaborative influenza surveillance. Report of a working group. Journal of Hygiene 75, 1.

REPORT (1971). Influenza - Respiratory disease surveillance. Centre for Disease Control Report No. 87. United States Department of Health, Education and Welfare. 